\title{
REPRESENTACIÓN SOCIAL DE LA HOMOSEXUALIDAD EN JÓVENES UNIVERSITARIOS CUBANOS
}

\author{
SOCIAL REPRESENTATION OF HOMOSEXUALITY IN YOUNG CUBAN UNIVERSITIES
}

\section{RESUMEN}

El presente estudio descriptivo, transversal, con enfoque metodológico cualitativo, con énfasis en la dimensión subjetiva, fue realizado en futuros profesionales de la carrera de Estudios Socioculturales que conviven en la Residencia Estudiantil de la Universidad Agraria de la Habana (UNAH), con el objetivo de realizar una caracterización en torno a las representaciones sociales que poseen estos jóvenes sobre la homosexualidad. Para llevar a cabo el estudio, las técnicas empleadas fueron la asociación libre de palabras, el dibujo, la escala de distancia social y la entrevista semiestructurada. Los principales resultados obtenidos evidencian que los sujetos estudiados muestran una actitud de aceptación hacia la diversidad sexual. Aun cuando los principales contenidos de representación giran en torno al reconocimiento de la discriminación social que sufren los homosexuales y el reclamo de la necesidad de aceptación social, son evidentes algunas consideraciones distorsionadas que continúan comprendiendo a la homosexualidad como una enfermedad y práctica antinatural.

Palabras clave: comprensión de la homosexualidad; homosexualidad; juventud; representación social.

\begin{abstract}
The present descriptive, traverse study, with qualitative methodological focus and emphasis in the subjective dimension, was carried out in future professionals of Social Cultural Studies Major, living at Agrarian University of Havana (UNAH) in the Student Residence with the objective to describe the social representation of homosexuality in the selected group. The techniques employed to perform the study were association free of words, drawing, scale of social distance and the semi structured interview. The main results obtained evidenced that the attitude toward the object of study is of high intensity acceptance. Even when the main representation contents deal with the recognition of social discrimination that homosexuals suffer and the claims of the necessity of social acceptance, some distorted considerations that understand homosexuality like an illness and an unnatural practice are evident.
\end{abstract}

Keywords: homosexuality; homosexuality's perception; social representation; youth.
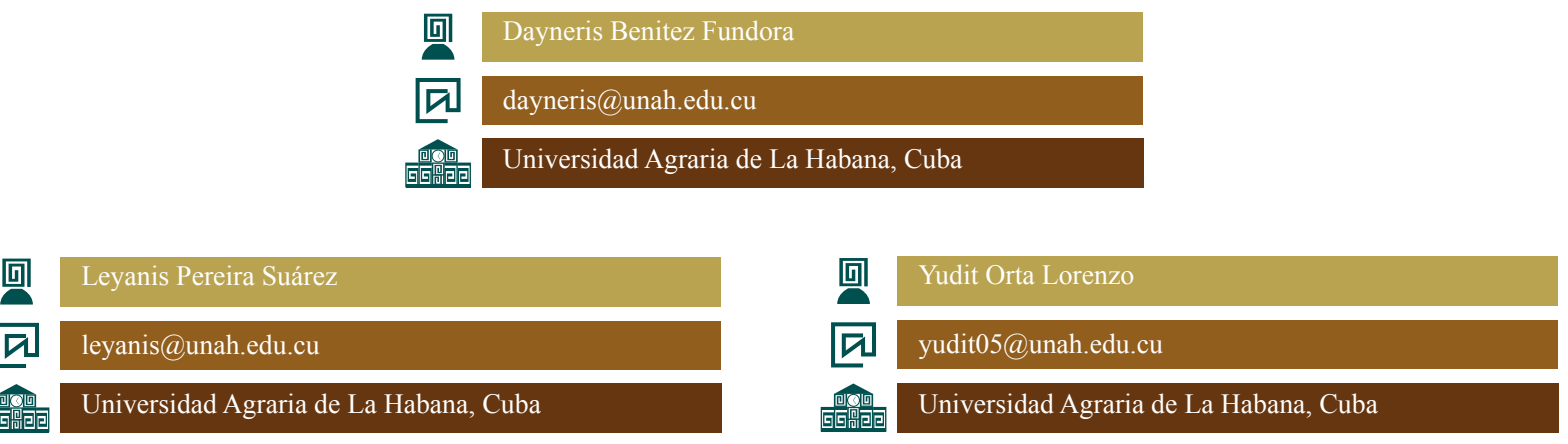


\section{INTRODUCCIÓN}

La sexualidad humana es uno de esos temas polémicos sobre los que más de una persona cree tener total conocimiento, cuando en realidad en no pocas ocasiones se asumen posturas reduccionistas que limitan su comprensión. Aún en nuestros días definirla va más allá de perspectivas individuales $\mathrm{y}$ continúa formando parte de ese imaginario rodeado de mitos, incógnitas, temores y prejuicios. Es por ello que con regularidad se acepta lo que ha sido heredado culturalmente como lo normativo, y se rechaza y denigra todo aquello que no forma parte de nuestras concepciones, valores y sistema de creencias, restringiendo así las posibilidades de aceptar la diversidad en lo que a orientación sexual se refiere.

La homosexualidad es una orientación sexual que tradicionalmente ha sufrido las consecuencias de estigmas y prejuicios sociales marcados por una cultura patriarcal, heterosexista, cuyas prácticas cotidianas en diversos escenarios tienden a soslayar la expresión de una sexualidad plural que refleja lo genuino de cada ser humano en su individualidad.

Según Moral (1997), la homosexualidad puede ser comprendida como la atracción preferencial a relacionarse afectiva y eróticamente con personas del propio sexo. Para clasificar de forma estricta a una persona como homosexual se requiere que presente deseo preferencial hacia personas del mismo sexo, haya tenido conductas homosexuales manifiestas (en ausencia o con dominio claro sobre la conducta heterosexual) y se identifique como homosexual.

Son diversas las declaraciones, eventos, conferencias, que se han realizado abogando por el derecho a la libre orientación sexual y la no discriminación hacia los homosexua- les, sin embargo, en gran medida, estas personas continúan siendo víctimas del aislamiento y rechazo por parte de la sociedad principalmente en países de América Latina y el Caribe. Es por ello que resulta válido cualquier intento en aras de formar valores encaminados hacia la asunción de conductas que potencien la igualdad y el respeto como derecho propio de cada sujeto, sin importar cuál sea su orientación sexual.

En este sentido se impone un gran reto no sólo en las relaciones interpersonales que se establecen en el ámbito público sino también en el espacio relacional más privado. La convivencia siempre ha resultado un tema complejo y problemático, que implica el respeto hacia los demás. Dicha convivencia resulta aún más compleja cuando se trata de aceptar la diversidad, en cualquiera que sea el ámbito donde tenga lugar, y cualquiera que sea la orientación sexual de las personas que conviven.

Hablar de convivencia implica acercarnos al mundo afectivo, moral y social de las personas, donde resulta de vital importancia el trato entre iguales, exigiendo el respeto mutuo y la aceptación entre sus miembros. En el caso de la convivencia, en una Residencia Estudiantil Universitaria, el proceso de formación de valores, hábitos, sentido de pertenencia y protagonismo estudiantil en la solución de problemas colectivos se obtiene gracias a la labor educativa y la formación del trabajo político-ideológico que se realice con los estudiantes, quienes comparten similares actividades socioculturales e interactúan entre sí de manera constante y sistemática.

En ocasiones la convivencia en una Residencia Estudiantil se convierte en un ambiente potencialmente psicopatógeno, puesto que puede conducir a un desarrollo personológico inadecuado de los sujetos que coexisten 
en este contexto, pertenecientes a la etapa evolutiva de la juventud. Dicha etapa del desarrollo se caracteriza por la consolidación de importantes formaciones psicológicas que, de no ser adecuadamente conducidas, pueden contribuir a que el joven sea más vulnerable a presentar problemas de autoestima, pobre autoconfianza, ineficientes relaciones interpersonales y pobre sentido de la autodeterminación. Es por ello que resulta de vital importancia realizar estudios encaminados a investigar el modo en que se producen las relaciones entre los jóvenes en este complejo y plural escenario.

Así, teniendo en cuenta la multiplicidad de características individuales y tomando como punto de partida el hecho de que en la convivencia a lo interno de la Residencia Estudiantil interactúan estudiantes con diversa orientación sexual, se legitima la necesidad de conocer las imágenes y creencias que comparten en torno al tema, lo cual es posible con la categoría representación social; que permite comprender y explicar la realidad compartida por estos jóvenes. Desde las representaciones sociales se propicia la comprensión de la esencia del pensamiento social, con un marcado énfasis en el cuestionamiento de los aspectos intrasubjetivos e intersubjetivos, destacando el valor del conocimiento cotidiano o del sentido común en los modos de actuación de los individuos.

La representación social es una modalidad particular del conocimiento, cuya función es la elaboración de los comportamientos y la comunicación entre los individuos (...) Es un corpus organizado de conocimientos y una de las actividades psíquicas gracias a las cuales los hombres hacen inteligible la realidad física y social, se integran en un grupo o en una relación cotidiana de intercambios... (Moscovici 1979, citado por Perera 2005:11-12)

En ellas se interpenetran las dimensiones cognitiva (elementos cognoscitivos asocia- dos a la comprensión del fenómeno), simbólica (imágenes y símbolos que evoca el objeto representacional en los sujetos estudiados) y actitudinal (predisposición a favor o en contra del objeto de representación, cuya intensidad puede ser mínima, moderada o máxima). Al propio tiempo las representaciones influyen en la toma de decisiones y en el posicionamiento de los grupos sociales ante determinados fenómenos de la realidad objetiva. Su comprensión se refiere a la dinámica existente a lo interno del grupo, a los modos en que el mismo piensa, siente y dota de sentido al entramado social desde su propia historicidad.

Entender esta postura conduce a dialogar con las ideas propuestas por González (2008), el cual profundiza en que las representaciones tejen sentidos psicológicos de la realidad más allá de lo instituido, en tanto son expresión de maneras muy particulares de comprender y posicionarse ante disímiles fenómenos.

Las representaciones sociales constituyen una producción de la subjetividad social capaz de integrar sentidos y configuraciones subjetivas que se desarrollan dentro de la multiplicidad de discursos, consecuencias y efectos colaterales de un orden social con diferentes niveles simultáneos de organización y con procesos en desarrollo que no siempre van en la dirección de las formas hegemónicas de institucionalización social. (González 2008:236)

Es decir, en palabras de Jodelet (1986), las representaciones mediatizan las prácticas cotidianas y son tanto un pensamiento constituido como constituyente; pensamiento constituido ya que se transforman en productos que intervienen en la vida social como estructuras preformadas que posibili- 
tan interpretar la realidad. Son pensamiento constituyente pues no sólo reflejan la realidad, sino que intervienen también en su elaboración.

Por medio del lenguaje se transmite todo el arsenal cultural que es determinante en la formación de las representaciones sociales, siendo los sujetos sociales productores de estos sentidos subjetivos (Martín y Perera 2001).

De esta forma, de acuerdo con Rodríguez (2001), se articulan las tres funciones básicas de la representación: función cognitiva de integración de lo novedoso, función de interpretación de la realidad, y función de orientación de las conductas y las relaciones sociales.

Ahora bien, a tono con este aparato teórico-metodológico, resulta de gran pertinencia el estudio sobre las producciones subjetivas que a modo de representaciones construyen los jóvenes universitarios investigados, puesto que dichas concepciones guían sus prácticas y brindan pistas sobre las que trabajar en pos de transformar nuestra realidad.

La investigación realizada tributa al proyecto de Transformación Sociocultural de la Residencia Estudiantil que se gesta en la Universidad Agraria de La Habana (UNAH), como parte de las acciones educativas llevadas a cabo en esta casa de altos estudios.

Los jóvenes que integran el grupo estudiado pertenecen a la carrera de Estudios Socioculturales, con la intencionalidad de explorar qué creencias, conocimientos, información, actitudes poseen acerca de la homosexualidad y puedan estar mediando su futura labor como cientistas sociales. Dentro del perfil profesional de esta carrera se destaca la promoción sociocultural, así como el trabajo social comunitario, cuya acción transformadora requiere de investigadores y gestores culturales que encaucen su accionar hacia la modificación de prácticas y esquemas mentales que se sustenten desde el conocimiento científico y no desde el sentido común y falsas creencias.

Al respecto Freyre (referido por Rojas y Rodríguez 2013), en su artículo titulado ¿Qué son los estudios socioculturales? señala que, de estos profesionales se espera que estén en condiciones de potenciar el desarrollo social autogestionario de las comunidades. Los futuros egresados de esta carrera contribuirán a la potenciación de procesos de construcción creativos, no limitados al consumo de bellas artes, sino desplazados a los espacios de la cotidianidad que permitan la búsqueda de una vida mejor. Razones estas que nos convocan a la formación de un profesional integral a la altura de estos tiempos.

En tal sentido se visualiza este trabajo investigativo como una aproximación necesaria en pos de la posterior realización de acciones educativas por parte de todos los trabajadores docentes y no docentes, que tributen al futuro desempeño profesional de estos estudiantes llamados a transformar nuestro entramado social en virtud de un proyecto social más inclusivo. Por todo ello, se plantea como objetivo general, la caracterización de la representación social de la homosexualidad que poseen los estudiantes becados pertenecientes a la carrera de Estudios Socioculturales. 


\section{METODOLOGÍA}

La presente investigación responde a una metodología mixta. Es un estudio descriptivo, en tanto se describirá el fenómeno tal cual se manifiesta, de corte transversal, que responde a la intención de detallar el fenómeno estudiado, poniendo énfasis en la comprensión e interpretación de los resultados obtenidos, fundamentalmente a la subjetividad de los individuos y a los significados que le atribuyen a la temática abordada.

A continuación se detallan los métodos y técnicas empleadas.

\section{En el nivel teórico}

Dialéctico-materialista: se encuentra presente en toda la investigación con el objetivo de dar un enfoque sistémico y en desarrollo del fenómeno en cuestión.

Histórico-lógico: nos posibilita llegar a la génesis de la función investigativa e indagar en su evolución sociohistórica, principales características y regularidades en cada etapa. En este caso, particularmente, posibilita conocer el tratamiento dado a la categoría representación social a lo largo de su desarrollo histórico y mediante el criterio de diversos autores.

Analítico-Sintético: este método se emplea para el análisis íntegro de la información obtenida, llevando a cabo una síntesis valorativa de la misma. Permite el análisis crítico acerca de los referentes teóricos en el abordaje del tema.

Inductivo-Deductivo: posibilita la generalización del análisis, determinando aspectos generales con respecto a la representación social y a la homosexualidad.

De esta manera se contribuye a la sistematización de la información obtenida acerca de la temática.

\section{En el nivel empírico}

Asociación libre de palabras: se caracteriza por el empleo de la palabra como estímulo ante el objeto de investigación a fin de que los individuos asocien ideas o frases con la palabra de estímulo. Se utiliza porque resulta muy eficaz para obtener los elementos componentes de una representación, lo que permite acceder al universo semántico del objeto de estudio y nos aproxima al núcleo figurativo y a los elementos periféricos que conforman el campo de la representación. Para ello se tiene en cuenta la frecuencia y el orden jerárquico en que se evocan las palabras o ideas en relación con la palabra de estímulo.

Dibujo: técnica proyectiva muy usada para el estudio de las representaciones sociales porque mediante la misma el sujeto ubica en el mundo externo una experiencia o imagen interna; contenidos estos que en ocasiones no pueden ser expresados verbalmente. El empleo de esta técnica permite obtener una representación simbólica, que exterioriza pensamientos e ideas más o menos abstractas, las cuales se interpretan de una manera cualitativa, de acuerdo a los indicadores estructurales y de contenido.

Escala de distancia social: consiste en establecer diversas alternativas o situaciones ante las que el sujeto debe expresar su proximidad o rechazo en una escala de posiciones. Mediante la técnica se requiere que los sujetos expresen el grado en que aceptarían a una persona homosexual para establecer determinadas y variadas formas de relaciones interpersonales.

Entrevista Semiestructurada: se utiliza fundamentalmente como recurso complementario para enriquecer la información obtenida, posibilitando profundizar en el universo semántico de los sujetos investigados. Esta técnica permite realizar valoracio- 
nes en cuanto a los juicios emitidos. Aporta una panorámica general acerca de la visión que se tiene del tema de la homosexualidad, las causas atribuidas, así como los significados asociados a la condición de ser homosexual y el tratamiento del tema en los últimos tiempos.

\section{En el nivel estadístico}

Método estadístico-matemático: mediante este se puede realizar la interpretación sistémica de datos aislados realizando inferencias; en este caso se emplea para procesar los resultados obtenidos con la aplicación de los instrumentos. Se utilizan los procedimientos estadísticos de frecuencia y el análisis porcentual.

\section{Definición de categorías de análisis}

Homosexualidad: atracción preferencial a relacionarse afectiva y eróticamente con personas del propio sexo. Para clasificar de forma estricta a una persona como homosexual se requiere que presente deseo preferencial hacia personas del mismo sexo, haya tenido conductas homosexuales manifiestas (en ausencia o con dominio claro sobre la conducta heterosexual) y se identifique como homosexual (Moral 1997).

Representación social:

...conocimiento de sentido común que se pone a disposición en la experiencia cotidiana; (...) construcciones con status de teoría ingenua, que sirven de guía para la acción e instrumento de lectura de la realidad; sistemas de significaciones que permiten interpretar el curso de los acontecimientos y las relaciones sociales; que expresan la relación que los individuos y los grupos mantienen con el mundo y los otros; que son forjadas en la interacción y el contacto con los discursos que circulan en el espacio público; que están inscritas en el lenguaje y en las prácticas; y que funcionan como un lenguaje en razón de su función simbólica y de los marcos que proporcionan para codificar y categorizar lo que compone el universo de la vida. (Jodelet 2000, citado por Perera 2005:47)

\section{Estructura en tres dimensiones}

1. Información: es la dimensión que da cuenta de los conocimientos en torno al objeto de representación.

2. Actitud: dimensión afectiva de la representación, que se entiende como una tendencia o predisposición adquirida, relativamente duradera, hacia el fenómeno objeto de representación.

3. Campo representacional: referido al orden y jerarquía que toman los contenidos representacionales, que se organizan en una estructura funcional determinada. El campo representacional se estructura en torno al núcleo o esquema figurativo y los elementos periféricos.

3.1. Núcleo Central: es la parte más sólida de la representación que determina su significación y organización, a través del cual que se crea y se transforma la significación del resto de los elementos constitutivos de la representación.

3.2. Elementos periféricos: se organizan alrededor del núcleo central y constituyen la interface entre el núcleo central y la situación concreta en la que se elabora o funciona la representación.

\section{Población y muestra seleccionada}

La población la constituyen los estudiantes que se encuentran becados en la Residencia Estudiantil UNAH (1168 estudiantes). De ellos fueron elegidos todos los estudiantes becados pertenecientes a la carrera de Estu- 
dios Socioculturales (criterio de inclusión), por el perfil profesional del egresado de dicha carrera, quedando conformado intencionalmente el grupo de estudio por los 22 estudiantes de la carrera que conviven en dicha comunidad. En el mismo se encuentran 6 estudiantes de primer año, 8 de segundo, 1 de tercero y 7 de cuarto año. De ellos, 6 son del sexo masculino y 16 del femenino, todos en un rango de edad comprendido entre 18 y 24 años.

\section{Procedimiento investigativo}

1. Fundamentar teórica y metodológicamente los presupuestos referidos al fenómeno de la representación social y de la homosexualidad.

2. Identificar los contenidos de la representación social de la homosexualidad en el grupo de estudio, atendiendo a las dimensiones: informacional (cognitiva), simbólica y actitudinal (afectivo-emocional).

3. Describir la estructura de la representación social de la homosexualidad en el grupo estudiado atendiendo a su núcleo figurativo y campo representacional.

\section{RESULTADOS INVESTIGATIVOS}

A continuación se presentan los resultados investigativos obtenidos.

\section{Asociación libre de palabras}

Con la finalidad de conocer las imágenes y producciones espontáneas que el objeto de estudio evoca en los sujetos, le fue presentada la palabra "homosexualidad", en calidad de estímulo. La libertad y espontaneidad al responder, sin la mediación del investigador, permite obtener una visión más objetiva y precisa de los contenidos representacionales.

Tras analizar el discurso de los sujetos se procedió a establecer categorías que agrupa- ran lo referido de acuerdo a su valor semántico y a los sentidos atribuidos, en aras de alcanzar una mayor comprensión de la subjetividad del grupo estudiado.

En tal sentido en un $54.5 \%$ se expresa que la condición de homosexualidad se define a partir de la orientación del deseo sexual hacia personas del mismo sexo. En este universo simbólico no sólo se evidencian expresiones relacionadas con las prácticas sexuales propiamente, sino que se hace alusión a las emociones y sentimientos condicionantes del vínculo entre iguales, resaltándose aspectos afectivos como la atracción y el deseo.

Desde esta óptica se comprende el término como: "unidad de géneros iguales", "amor por su mismo sexo", "vínculo sexual de dos personas que poseen igual sexo", "persona que se siente atraída o atraído por la forma de ser de una persona de su mismo sexo".

Otra perspectiva de análisis apunta a que el $36.4 \%$ comparte opiniones acerca de la naturaleza de las relaciones homosexuales, ofreciendo una valoración permeada de juicios negativos y excluyentes. En correspondencia con ello fue construida la categoría Carácter antinatural de la relación homosexual, en la que se considera al fenómeno como una desviación, problema e incluso una enfermedad.

Los sujetos plasman ideas en su definición de la homosexualidad como: "preferencia sexual diferente a lo socialmente establecido", "personas ridículas, con problemas", "individuos sociales que no comparten el gusto natural", "enfermedad que afecta a la sociedad".

Tal comprensión reduccionista de la sexualidad se centra en concebir a la heterosexualidad como lo "normativo", "el deber ser" en materia de comportamiento sexual en los 
seres humanos. Ello es expresión de cánones vigentes en la sociedad, que históricamente han legitimado a la heterosexualidad como única orientación del deseo sexual posible de ser manifiesta con total aceptación. Estas concepciones homofóbicas tan arraigadas aún en la Cuba de estos tiempos, se reproducen acríticamente en diversos ámbitos de actuación, en tanto expresión de la herencia cultural legada de procesos de colonización y transculturación inscritos en nuestra historia.

No obstante a ello, se puede enunciar que con un porcentaje menor $(22.7 \%)$, desde diversos marcos interpretativos, algunos sujetos reconocen los estigmas asociados a la homosexualidad y las prácticas sociales excluyentes que históricamente han marcado una visión hegemónica del fenómeno desde lo cultural, a pesar de la no existencia de políticas sociales en Cuba que legitimen la más mínima manifestación de discriminación.

En esta categoría denominada discriminación hacia la homosexualidad por parte de la sociedad, el grupo discursa en torno a los estereotipos y prejuicios que acompañan a las personas homosexuales, sosteniendo que: "son personas reprimidas, marginadas", "víctimas de prejuicios sociales y de burlas".

Vale destacar que solo en el $4.5 \%$ de los casos, se repara en visualizar a las personas gays y lesbianas con cualidades y actitudes positivas, considerándose como un Grupo demandante de comprensión genuina.

Ahora bien, resulta curioso identificar que más allá de los criterios a favor o en contra de la homosexualidad que sostienen los miembros del grupo estudiado, en un 45.5\% se realiza un reclamo en pos de la necesidad de aceptación social hacia las personas con una orientación sexual diferente. Se enun- cian frases en función de lograr el respecto colectivo a la decisión personal en cuanto a los modos particulares de vivir la sexualidad, donde la diversidad no sea un obstáculo de convivencia entre los seres humanos. Ejemplo: "los homosexuales son seres humanos con derecho e igualdad de elegir", "no deben ser señalados, juzgados, discriminados o maltratados por sus diferencias", "tienen el derecho a vivir su vida como quieran sin tener que ser víctimas de prejuicios".

A modo de síntesis se puede decir que existe consenso en el grupo estudiado acerca de la definición del fenómeno, siendo compartida la concepción de que la homosexualidad es una orientación diferente a lo aceptado socialmente en materia de comportamiento sexual. Algunos sujetos apuntan a que desde lo biológico y lo cultural, la homosexualidad constituye una práctica antinatural acompañada de una valoración social negativa. Además de ello, un por ciento no tan representativo pero ilustrador de las imágenes que se tienen al respecto, reconoce la discriminación por orientación sexual como un fenómeno que existe en la sociedad civil cubana. En tal sentido, a pesar de ciertas posturas de incomprensión al grupo LGBT (Lesbianas, Gais, Bisexuales y Transexuales), los sujetos estudiados refieren en gran medida la necesidad de su aceptación social, puesto que ya es un hecho estéril su negación o repudio. Todos estos criterios emergen de manera espontánea sintetizando las maneras en que se representa el fenómeno a nivel del grupo investigado.

\section{Dibujo}

La riqueza simbólica generada por los participantes mediante trazos, líneas y exposiciones gráficas muestra en su mayoría una representación icónica de la relación de pareja entre personas del mismo sexo, siendo posible apreciar diversidad en lo que a tipo de homosexualidad se refiere. En este 
sentido el $11.1 \%$ se representa la homosexualidad femenina, el 22.2\% la homosexualidad masculina y el $66.7 \%$ se representa ambos tipos de homosexualidad.

Este resultado se contrapone a lo encontrado por Álvarez en el año 2011, en cuyo estudio con un grupo de futuros profesionales de la salud (que cursaban las especialidades de Estomatología, Enfermería, Medicina y Psicología), encontró que el $100 \%$ de los estudiantes se representaron la homosexualidad limitada al homosexual masculino, dando muestras de los estereotipos que existen en la sociedad respecto al tema, soslayándose la presencia de la homosexualidad femenina, la cual históricamente ha sido visibilizada en menor medida, siendo hoy más percibida.

Desde otra arista emerge en los dibujos la categoría signada como discriminación por parte de la sociedad, para representar las actitudes de rechazo hacia las personas homosexuales. En las producciones simbólicas el $31.8 \%$ de los sujetos reconocen y reflejan que la homosexualidad, en nuestra sociedad, continúa estando lejos de la aceptación total. Muestran de este modo a una sociedad prejuiciada, machista y poco flexible ante la diversidad sexual. Al respecto se colocan frases cuyos contenidos evidencian violencia verbal y la segmentación marcada por las diferencias en la orientación sexual.

Muy relacionado con el reconocimiento de la discriminación social hacia la homosexualidad, se presenta en un $36.4 \%$ de los sujetos el reclamo a la necesidad de aceptación social hacia la comunidad LGBT, a ser reconocidos en su condición de seres humanos, poseedores de valores y en igualdad de derechos en la expresión libre de su sexualidad, que a decir de ellos: "deben ser igualmente aceptados en la sociedad", "tienen el derecho de elegir libremente y que no deben, ni tienen que darle explicación a nadie de lo que está bien o mal a la hora de elegir su pareja".

A diferencia de lo encontrado en la asociación libre de palabras, donde al referirse a la igualdad e integración lo exponían únicamente en términos de necesidad de aceptación social, en esta técnica se da en el 40.9\% de los sujetos aceptación y reconocimiento de los homosexuales no sólo en calidad de seres sociales que necesitan ser aceptados y comprendidos, sino como personas, centrándose en el valor que poseen como seres humanos, referidos en los siguientes criterios: "son personas normales y corrientes", "individuos sociales, igual al resto".

Los símbolos representados al respecto ponen de manifiesto que no existe diferencia entre las personas homosexuales y heterosexuales, pues todos pertenecen a una categoría que los trasciende: la de seres humanos.

Este resultado es de vital importancia, pues evidencia que un elevado número de los sujetos estudiados se muestran "despojados" de los prejuicios que siguen denigrando $\mathrm{y}$ marginando a las personas homosexuales, apostando por su integración indiferenciada en la sociedad.

No obstante, a pesar de la labor desplegada en nuestro país en aras de la inclusión social y aceptación en igualdad de condiciones y derechos, el $22.3 \%$ de los sujetos considera que el vínculo erótico-afectivo entre iguales posee un carácter antinatural, al representar simbólica y discursivamente a la homosexualidad como una enfermedad, un comportamiento diferente a lo culturalmente considerado "normativo", incluso resaltándose la práctica homosexual como una desviación. Modos estos de comprensión del fenómeno que expresan una cultura que entroniza a la 


\section{Unach}

heterosexualidad como única vía de orientación del deseo sexual, estigmatizándose todo comportamiento que emerja en calidad de alternativa ante tal referente explicativo.

En sentido general los resultados hallados reflejan que queda mucho por hacer en materia de educación hacia una cultura del respeto por lo diverso, el camino aún es largo, pues aunque se aboga por la no discriminación y la aceptación, se producen contradicciones explícitas que denotan

Tabla 1: Perfil grupal de la escala de distancia social

\begin{tabular}{|c|c|c|c|c|c|c|}
\hline $\begin{array}{l}\text { Relación } \\
\text { como: }\end{array}$ & $\%$ RAI & $\%$ RBI & $\begin{array}{l}\text { Total } \\
\text { Rechazo }\end{array}$ & $\%$ ABI & $\%$ AAI & $\begin{array}{l}\text { Total } \\
\text { Aceptación }\end{array}$ \\
\hline Vecino & & & & 27.3 & 72.7 & 100 \\
\hline $\begin{array}{l}\text { Compañero de } \\
\text { Trabajo }\end{array}$ & & 13.6 & 13.6 & 22.7 & 63.7 & 86.4 \\
\hline Pareja & 100 & & 100 & & & \\
\hline Jefe & 13.6 & & 13.6 & 27.3 & 59.1 & 86.4 \\
\hline $\begin{array}{l}\text { Compañero de } \\
\text { Diversiones }\end{array}$ & 18.2 & 18.2 & 36.4 & 40.9 & 22.7 & 63.6 \\
\hline Maestro & & & & 27.3 & 72.7 & 100 \\
\hline $\begin{array}{l}\text { Prestador de } \\
\text { Servicios }\end{array}$ & & & & 40.9 & 59.1 & 100 \\
\hline Amigo & 13.6 & 13.6 & 27.2 & 18.2 & 54.5 & 72.8 \\
\hline Hijo & 27.3 & 13.6 & 40.9 & 13.6 & 45.5 & 59.1 \\
\hline $\begin{array}{l}\text { Compañero de } \\
\text { Estudio }\end{array}$ & 22.7 & & 22.7 & 22.7 & 54.5 & 77.3 \\
\hline $\begin{array}{l}\text { Pareja de sus } \\
\text { Hijos }\end{array}$ & 31.8 & 27.3 & 59.1 & 18.2 & 22.7 & 40.9 \\
\hline $\begin{array}{l}\text { Compañero de } \\
\text { Cuarto }\end{array}$ & 22.7 & 22.7 & 45.4 & 18.2 & 36.4 & 54.6 \\
\hline
\end{tabular}

Fuente: elaboración propia. 
rechazo hacia la homosexualidad. Ello cobra mayor importancia cuando estas actitudes excluyentes se manifiestan en personas jóvenes, futuros educadores de las generaciones venideras, y en este caso futuros profesionales de las ciencias sociales.

\section{Escala de Distancia Social}

Esta técnica posibilita evaluar la dimensión actitudinal ante el objeto de representación, valorando el grado de proximidad o rechazo hacia las personas homosexuales en diferentes situaciones de relaciones interpersonales.

El análisis de los por cientos obtenidos, determinados por las opciones marcadas por los sujetos, hizo posible obtener el perfil grupal, denotando, en cada situación el grado de aceptación o rechazo hacia el objeto de estudio. Así, fue posible determinar cuándo se daba rechazo de alta intensidad (RAI); rechazo de baja intensidad (RBI); aceptación de baja intensidad (ABI) o aceptación de alta intensidad (AAI), de acuerdo a la alternativa seleccionada por ellos para evaluar si aceptarían o no relacionarse con personas homosexuales en diferentes tipos de relaciones interpersonales. El perfil grupal se puede apreciar en la tabla 1.

Este perfil muestra que la disposición general de los sujetos hacia la homosexualidad es una actitud que aboga por la aceptación. Estos datos invitan a pensar que las concepciones acerca del fenómeno en la sociedad, se están reconfigurando paulatinamente, transitando desde posiciones convencionales marcadamente heterosexistas hacia posturas abiertas a la comprensión del mismo.

No obstante, estos resultados de la disposición global no pueden interpretarse como una aceptación total de la homosexualidad, pues al analizar situaciones específicas, se puede encontrar que existen relaciones en espacios de gran cercanía o proximidad, que si bien no determinan un rechazo total, ofrecen muestras significativas de no aceptación. Por ello se puede expresar que la aceptación es restringida, construyéndose límites que preservan los espacios de interacción más íntimos, visualizándose una aceptación con "ciertas condiciones".

En lo que respecta a las relaciones de pareja, se evidencia la no aceptación de personas homosexuales en el $100 \%$ de los casos, lo cual nos muestra rechazo de alta intensidad en uno de los espacios más privados de intercambio con un "otro". Por tanto la actitud totalmente negativa se palpa cuando se trata de visualizar que la pareja propia pudo haber tenido prácticas homosexuales en el pasado. En cambio cuando se trata de evaluar la aceptación de un amigo en su condición de homosexual, se evidencia una actitud favorable.

Por otra parte, resultados significativos que evidencian una disposición de rechazo tanto de alta como baja intensidad hacia la homosexualidad, se encuentran en las relaciones con los hijos (40.9\%) y las parejas de los hijos (59.1\%), así como con los compañeros de cuarto en la Residencia Estudiantil (45.4\%).

En cuanto a la asunción de una postura hacia la aceptación o el rechazo en el caso de los hijos $(40.9 \%)$ y las parejas de los hijos (59.1\%), se puede decir que el grupo se encuentra dividido, manifestándose una dualidad de criterios al respecto que es expresión de las controversias aún palpables desde lo social en relación al objeto representacional. En tal sentido, en cuanto a la relación con el hijo, los sujetos se dirigen más hacia el polo de la aceptación pero con cierta "discreción", perspectiva mediatizada por patrones culturales, caracterizándose la 
familia cubana desde su historicidad por ser mayoritariamente "paternalista" en la asunción de los roles paternos y maternos, lo cual explica el hecho de expresar menor rigidez cuando se valora a los hijos en comparación con las parejas de estos. La comprensión del fenómeno en el marco de las relaciones paterno-filiares es coherente con las expectativas sociales que se depositan en torno a los roles parentales, aunque vale destacar que un elevado número de sujetos se posicionó negativamente al respecto.

De acuerdo al criterio esgrimido en cuanto a la aceptación en el marco del espacio de la Residencia Estudiantil, si bien el 54.6\% de los sujetos evidenció muestras de aceptación, no se debe desestimar el criterio de aquellos que no se pronunciaron en esta dirección. Teniendo en cuenta que el presente estudio se realizó en la Residencia Estudiantil UNAH, que constituye un espacio de convivencia comunitaria donde sus miembros deben compartir los cuartos con otros estudiantes, resulta importante llamar la atención sobre este resultado. El mismo evidencia uno de los más altos índices de rechazo al tener que relacionarse con personas con una orientación sexual homosexual.

Esta comunidad, como cualquier otra, no se encuentra exenta de contar entre sus miembros con personas homosexuales, que, teniendo en cuenta los resultados mostrados, muy probablemente estén siendo víctimas de marginación e irrespeto por parte de algunos de sus compañeros. Aunque esta idea no sea concluyente, no se debe obviar su posibilidad. De ser así, este espacio de convivencia estaría constituyendo un lugar potencialmente dañino para el bienestar y adecuado desarrollo personal de las personas homosexuales.

Todos estos resultados presuponen que las relaciones con los homosexuales aún se ven permeadas por prejuicios y estereotipos, pues la aceptación se da en mayor medida desde lejos, cuando la cercanía al objeto representacional no presupone vínculos en marcos muy estrechos.

\section{Entrevista Semiestructurada}

La entrevista fue realizada con la pretensión de valorar los juicios emitidos por los sujetos, que permitan enriquecer lo referido en otras técnicas. En este sentido fue explorado en primera instancia el nivel de cercanía con el objeto de representación. Además se indagó en la significación concedida a la homosexualidad, las causas que se le atribuyen a la misma, así como las valoraciones que poseen respecto al modo en que se aborda el tema.

Como primer resultado se constató que el $77.3 \%$ de los sujetos poseen vínculo con personas homosexuales, en calidad de amigos, familiares o compañeros. Sólo el $22.7 \%$ refiere no poseer vínculo de ningún tipo con homosexuales. Esto refleja que la gran mayoría posee determinado nivel de cercanía con el objeto de representación.

Los criterios emitidos en relación a cómo son los homosexuales se centran en los comportamientos que estos asumen ante la sociedad, primando criterios y valoraciones negativas, que ven a los homosexuales como personas cuya conducta es inapropiada e indebida para mostrarse socialmente. Algunos de los criterios expresados al respecto son: "sus comportamientos son horrendos", "egocéntricos", "vulgares", "exagerados", "a veces un poco trágicos", "les cuesta trabajo integrarse a la sociedad".

También se identifican por características externas refiriendo que su aspecto físico es contrario a su sexo, mostrándose una visión estereotipada: "si son mujeres homosexuales tienen el pelo corto y las uñas cortas, se arreglan poco", "si son hombres homosexuales 
tienen movimientos y voz afeminada y ciertas modas femeninas notables".

Algunos refieren atributos y valores positivos que los reconocen como seres humanos, con los mismos derechos que los heterosexuales, y resaltan, aunque en menor medida, cualidades morales que los hacen ser buenos amigos. Esto se evidencia en criterios como: "son seres humanos como cualquier otro", "personas con valores y cualidades", "agradables", "divertidos" y "cultos".

En relación al significado que le atribuyen a ser homosexual, resulta significativo, que tal como se refleja en las restantes técnicas aplicadas, las respuestas están encaminadas básicamente a la definición del término, de acuerdo a su carácter sexual. Se representan la homosexualidad como la relación que se da entre personas de igual sexo, pero sin dejar de considerar la atracción y el deseo como elementos que determinan la conducta homosexual, pues la describen en términos de orientación sexual, preferencia, atracción, o gusto.

Uno de los sujetos lo simboliza con una cárcel, reflejando de este modo la angustia por la falta de libertad y de aceptación. En correspondencia se expresan las consecuencias de ser homosexual, pues según los sujetos estudiados, esta condición trae consigo incomprensión, rechazo, tristeza, conflictos, así mismo se le atribuye como significado la valentía al enfrentarse al mundo y luchar por sus derechos, lo que destaca el esfuerzo que realizan los homosexuales en su lucha por lograr ser reconocidos como tal sin mediaciones prejuiciosas. Algunos de los criterios emitidos y que evidencian estos significados son: "producto de la marginación a la que se encuentran sometidos, algunos se automarginan", "significa aceptarse tal como es y enfrentar al mundo".
Referido a las causas de la homosexualidad las respuestas son variadas. Algunos sujetos refieren el papel de la genética y de los factores hormonales como agentes desencadenantes de la homosexualidad: "nacen así", "producto de un trastorno hormonal".

Los factores psicológicos también emergen como causas atribuidas a la homosexualidad, fundamentalmente la teoría conductual, pues se representan la homosexualidad como algo que se aprende por el condicionamiento social: "es por la influencia social", "por intereses económicos", "por moda".

Estas causas atribuidas a la homosexualidad emergen en menor medida, puesto que mayoritariamente las respuestas de los sujetos se limitan a expresar que se debe a una elección personal, sin causa específica, al referir que es: "porque les gusta", "lo prefieren", "lo deciden asín".

Esta representación sobre las causas de la homosexualidad, al decir de Soriano (1999), tiende a ser una creencia extendida en la sociedad, sin embargo los estudios que se han realizado al respecto, niegan esta concepción.

Por último, relacionado con la forma en que se aborda el tema de la homosexualidad, también se encuentra dicotomía en los criterios expresados, reflejo de las contradicciones que se encuentran en la representación social de estos sujetos sobre este objeto, pues se dividen entre los que consideran que el abordaje del tema es adecuado y los que opinan que es inapropiado.

Los criterios positivos son: "hablan del tema en pro de la no exclusión", "se aborda de manera profunda, con sentimiento y claridad", "provoca que la sociedad poco a poco los vaya aceptando", "los sports televisivos resultan novedosos", "los medios de comu- 
nicación lo abordan de manera clara y objetiva, con sistematicidad".

Los criterios negativos refieren que: "hay demasiado libertinaje", "provocan que los indecisos se inclinen hacia ahí", "a veces es demasiado", "se le da demasiada prioridad al tema, cuando hay otros más importantes", "se aborda de manera superficial y reduccionista".

Resulta interesante que al referirse al modo en que se aborda el tema, el 100\% de los sujetos se centra única y exclusivamente en la labor realizada por los medios de comunicación masiva (dígase $\mathrm{TV}$, radio y prensa), legitimándose el poder que tienen estos en la construcción de las representaciones sociales. En tal sentido se deja fuera la labor desplegada por las instituciones sociales de educación y salud. Este hecho apunta al no reconocimiento de estas instituciones en el tratamiento del tema, lo que deviene en llamado de alerta, ya que estas instituciones son escenarios de vital importancia de cara a la educación de la población.

\section{DISCUSIÓN DE LOS RESULTADOS}

Un análisis desde el punto de vista de las dimensiones cognitiva, simbólica y actitudinal nos permite visibilizar que:

\section{Dimensión Cognitiva}

Desde el punto de vista cognitivo, las concepciones que poseen los sujetos estudiados en relación a la homosexualidad tienen puntos de contacto con lo planteado en la literatura científica. En este sentido tienden a considerar la homosexualidad como aquella relación que se establece entre personas de igual sexo, pero los significados atribuidos no se limitan sólo al aspecto sexual, sino que reconocen que se trata de una orientación sexual basada en una atracción preferencial. Además se representan tanto la homosexualidad femenina como la masculina.

Relacionado con las causas de la homosexualidad se evidencia diversidad de criterios. Algunos refieren causas de tipo biológicas, al expresar que nacen así, o se trata de un problema hormonal; mientras que otros reflejan causas psicológicas como el aprendizaje o condicionamiento social. En cambio, la representación más compartida en relación a este tema es que se ubican las causas de la homosexualidad en una cuestión de elección personal. Estos criterios, si bien no están demostrados y resultan contradictorios con estudios científicos realizados al respecto, constituyen una representación bastante extendida en la población según refiere Soriano (1999). Lo cierto es que aún, desde el punto de vista especializado, no se sabe con exactitud cuáles son las causas que condicionan la homosexualidad.

Por otra parte, la percepción que tienen estos jóvenes de las personas homosexuales se limita fundamentalmente a aspectos negativos de su comportamiento, resaltando que muestran una conducta inapropiada y diferente. Sólo una pequeña minoría resalta atributos y cualidades positivas señalando los valores morales que pueden poseer.

En síntesis, podemos decir que a pesar de toda la información que el grupo tiene, es posible apreciar que subyacen algunas concepciones erróneas pues aún algunos consideran a la homosexualidad como una enfermedad y una desviación sexual; concepciones estas que se encuentran condicionadas socialmente, pues son los comportamientos que ven y lo que escuchan en diversos espacios de intercambio social los 
que marcan sus opiniones. $Y$ es que, a pesar de toda la labor que realizan los medios de comunicación y las instituciones cubanas, lo cierto es que aún la sociedad discrimina a los homosexuales y la idea de desviación y enfermedad se mantiene fuertemente enraizada en el imaginario popular.

Al propio tiempo se hace un llamado a las instituciones educativas, de salud y a los medios de comunicación a perfeccionar la labor educativa que realizan en este sentido, puesto que la mayoría de estos jóvenes no reconoce ni legitima la impronta de su accionar en la desconfiguración de los prejuicios que persisten en los diferentes grupos de la sociedad cubana con independencia del nivel educativo, el sexo o el color de la piel.

\section{Dimensión Simbólica y Actitudinal}

Los jóvenes reconocen la discriminación y marginación que sufren las personas homosexuales, al tiempo que reflejan las necesidades de igualdad y aceptación, representando tanto simbólica como discursivamente la importancia de la integración de los homosexuales a la sociedad.

Sin embargo, en este sentido es posible apreciar una actitud contradictoria, puesto que producto de los propios tabúes y prejuicios que prevalecen en la sociedad y de los cuales ellos no se encuentran exentos, se evidencia distancia emocional y poca implicación afectiva.

En sentido general, se percibe que la representación en torno a esta temática se está reconfigurando paulatinamente, transitando desde posiciones convencionales marcadamente heterosexistas hacia posturas abiertas que evidencian aceptación. En este sentido se aprecia que la aceptación es restringida, construyéndose límites que preservan los espacios de interacción más íntimos, visualizándose una aceptación con "ciertas condiciones". Resultados significativos apuntan a expresar cierto rechazo cuando el vínculo con la persona homosexual tiene lugar en ámbitos tan privados como la familia y la habitación que comparten en la Residencia Estudiantil en su condición de becados.

Resulta importante llamar la atención sobre este resultado ya que a lo interno de la comunidad universitaria existen estudiantes homosexuales que pudieran ser víctimas de marginación e irrespeto por parte de algunos de sus compañeros. Aunque esta hipótesis no sea concluyente, no se debe obviar su posibilidad. Todos estos resultados presuponen que, desde la perspectiva de los jóvenes estudiados, las relaciones con las personas homosexuales se ven permeadas por prejuicios y estereotipos, pues a pesar de la labor intencionada que se realiza de cara a la aceptación de la diversidad sexual, esta se expresa en mayor medida desde lejos, o sea cuando la cercanía al objeto representacional no presupone vínculos en marcos de interacción muy estrechos.

De ahí que queda mucho por hacer en materia de educación hacia una cultura del respeto por lo diverso, pues aunque se aboga por la no discriminación y la total aceptación, se producen contradicciones tanto discursivas como comportamentales que reflejan en su mayoría matices de rechazo hacia la homosexualidad. Ello cobra mayor importancia cuando estas actitudes se manifiestan en los jóvenes de hoy, llamados a transformar su sociedad en un espacio más justo e inclusivo.

\section{Campo Representacional}

Los contenidos que integran el campo representacional se organizan de la siguiente manera:

Como parte más sólida de la representación y por tanto, conformando el núcleo representacional, se señalan como significados 
que con mayor valor y frecuencia emergieron los referidos a la concepción de la homosexualidad como orientación del deseo sexual que presupone la relación entre personas del mismo sexo, sin dejar de reconocer las emociones y sentimientos que condicionan el vínculo entre estas personas.

Otros significados que afloraron como elementos que componen el núcleo de la representación social de la homosexualidad en los sujetos estudiados son los referidos al rechazo social y la discriminación a la que están sometidos los homosexuales a causa de los prejuicios y tabúes sociales, por lo que emergen como reclamos de los sujetos de estudio una mayor comprensión y aceptación social del fenómeno.

En este sentido se produce una contradicción, puesto que como elementos sólidos se evidencian actitudes desfavorables de incomprensión del fenómeno, resaltando a los homosexuales como diferentes, enfermos y desviados; a pesar que la dirección global de la actitud es hacia la aceptación, aunque con ciertas limitaciones. Resulta paradójico que las mismas personas que abogan por una mejor comprensión a la vez muestren estas actitudes de desavenencia.

A pesar de los conocimientos referidos y de la cercanía al objeto representacional la aceptación del mismo supone una tolerancia desde fuera, como algo que debe ser comprendido, pero con poca implicación emocional-afectiva.

Como parte de los elementos periféricos se encuentran las causas asociadas a la homosexualidad; el reconocimiento de la labor de los medios de comunicación en el tratamiento del tema, no siendo identificados otros agentes de socialización significativos como la escuela, la familia y las instituciones de salud. Se encuentran además los significados que se le atribuyen a las consecuencias de ser homosexual, reflejando el malestar que vivencian estas personas por su condición de homosexual, mediatizadas por influencias sociales excluyentes. Otros elementos que afloraron son los referidos a los rasgos físicos que los tipifican, desde la asunción de estereotipos sociales. Relacionado con esto se refieren a los comportamientos que asumen los homosexuales ante la sociedad concebidos como excéntricos, además se puntualizan rasgos personológicos como la alegría y un elevado nivel cultural.

A grandes rasgos, los resultados investigativos permiten apreciar que a pesar de que se van produciendo cambios mentales importantes en las nuevas generaciones, que denotan una mayor comprensión y asimilación de la homosexualidad como una práctica sexual legítima, aún hay comportamientos y actitudes en la sociedad cubana excluyentes en lo que a homosexualidad se refiere. La herencia que históricamente nos ha sido legada, y que supone ideas, prejuicios, estereotipos y tabúes, se encuentra tan fuertemente arraigada que resulta difícil para muchas personas asumir a la homosexualidad como una manera más de ser y vivir la sexualidad.

\section{CONCLUSIONES}

Al finalizar la investigación se ha llegado a las siguientes conclusiones:

\section{En la Dimensión Cognitiva}

Los contenidos de la representación social de la homosexualidad presente en los sujetos estudiados evidencian que los significados atribuidos al objeto de estudio se focalizan en la concepción del término como relación sexual y afectiva que se establece entre personas de igual sexo, reconociendo tanto la homosexualidad masculina como la femenina. 


\section{Unach}

Persisten algunas concepciones erróneas al percibir la homosexualidad como una enfermedad y práctica antinatural.

Las causas atribuidas a la homosexualidad resaltan tanto factores biológicos como psicológicos, así como de que se trata de una elección personal.

\section{En la Dimensión Simbólica-Actitudinal}

Simbólicamente se representan la homosexualidad como la relación entre personas del mismo sexo, que son discriminados por la sociedad, por constituir una orientación sexual diferente a la aceptada como "natural", por lo que se expresa la necesidad de integrar a los homosexuales a la sociedad como los seres sociales que son.

Se obtuvo como disposición general de los sujetos hacia la homosexualidad, una actitud de aceptación de alta intensidad. Sin embargo, fue posible apreciar que la aceptación se da en mayor medida desde lejos, cuando la cercanía al objeto representacional no presupone vínculos en marcos estrechos.

\section{En el Campo Representacional}

En el núcleo figurativo se centran como elementos más significativos: la concepción de la homosexualidad como una orientación sexual, el reconocimiento del rechazo y la discriminación social que sufren los homosexuales, la necesidad de comprender y aceptar el fenómeno, así como criterios en contraposición a los anteriores, basados en falsas creencias que resaltan a los homosexuales como diferentes, enfermos $y$ desviados.

En la periferia se encuentran elementos referidos a la diversidad de causas asociadas a la homosexualidad, la labor de los medios de comunicación en la divulgación del tema, que constituye además una de las principales vías de obtención del conocimiento, los significados atribuidos a las prácticas homosexuales (negativos en su mayoría) y las consecuencias de ser homosexual en la sociedad actual. 


\section{REFERENCIAS BIBLIOGRÁFICAS}

Álvarez, G. (2011). Representaciones Sociales de la homosexualidad en futuros profesionales de la salud (Tesis de Licenciatura inédita). Facultad de Ciencias Médicas de Mayabeque, Cuba.

González, F. (2008). Subjetividad social, sujeto y representaciones sociales. Revista Diversitas- Perspectivas en Psicología, 4(2), 225-243.

Jodelet, D. (1986). La Representación Social: fenómenos, concepto y teoría. Resumen de la obra de Moscovici. Revista Psicología Social, (2), 469-494.

Martín, C., \& Perera, M. (2001). Representaciones sociales de la vida cotidiana en Cuba. Revista Cubana de Psicología, 18(1), 34-45.

Moral, J. (1997). Una propuesta explicativa integradora de la conducta homosexual. Revista REME, 13(34), s.p.

Perera, M. (2005). Sistematización crítica de la teoría de las Representaciones Sociales (Tesis de Doctorado inédita). Centro de Investigaciones Psicológicas y Sociológicas, Cuba.

Rodríguez, O. (2001). Representación social del alcoholismo (Tesis de Licenciatura inédita). Universidad de La Habana, Cuba.

Rojas, B. \& Rodríguez, L. (2013). Lo sociocultural: un trabajo pendiente. Cuba: Editorial Ciencias Sociales.

Soriano, S. (1999). Cómo se vive la homosexualidad y el lesbianismo. Salamanca, España: Ediciones Amaru.
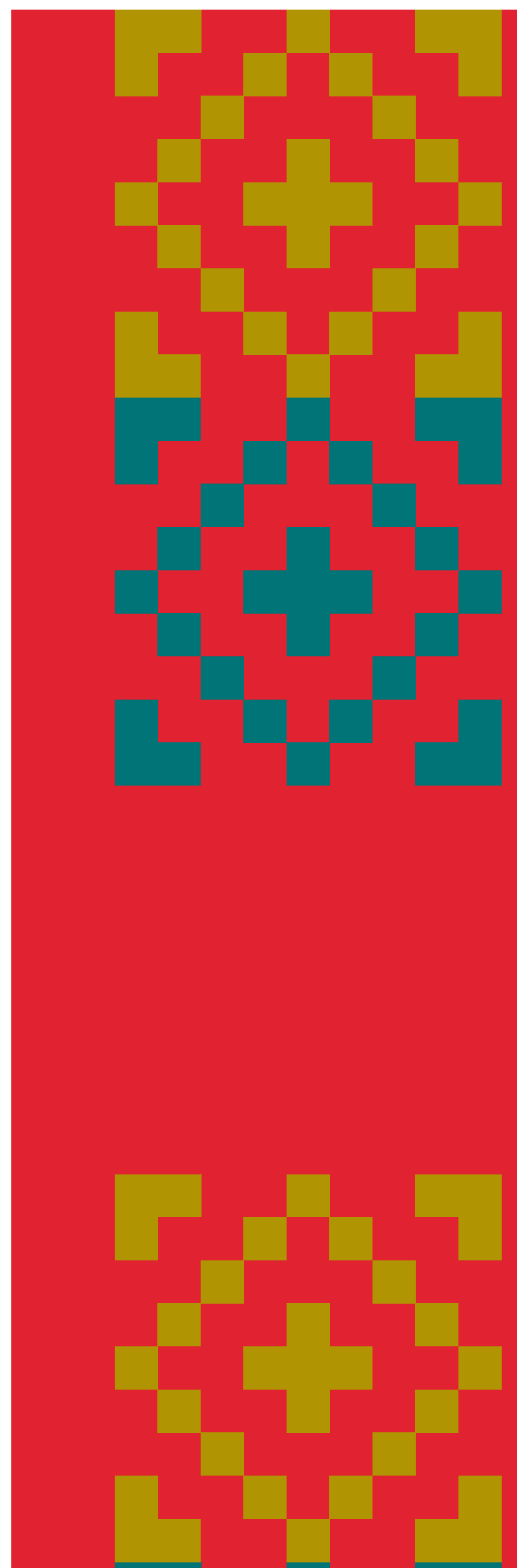